\title{
Clinical variability of the systemic juvenile idiopathic arthritis course: literature review based on case series
}

\author{
Oksana Boyarchuk ${ }^{1}$, Tetiana Kovalchuk ${ }^{1}$, Nataliya Kovalchuk ${ }^{1}$, Oksana Chubata ${ }^{2}$ \\ ${ }^{1}$ Department of Children's Diseases and Pediatric Surgery, I. Horbachevsky Ternopil National Medical University, Ternopil, Ukraine \\ ${ }^{2}$ Ternopil Regional Children's Hospital, Ukraine
}

\begin{abstract}
Systemic juvenile idiopathic arthritis (SIIA) is a heterogeneous category of arthritis that frequently leads to disability and severe complications. The clinical cause of sJIA is very variable, which results in difficulties of disease recognition.

In this literature review based on case series we outline the main challenges in diagnostic of sJIA and macrophage activation syndrome (MAS). Using the 2016 criteria for MAS diagnostic allowed to consider MAS in the diagnostically challenging cases, that confirms their sensitivity in pediatric patients. The reviewed literature showed last updates for the improvement of classification, diagnostic of sJIA and its complication. The modification of JIA criteria, initiated by Paediatric Rheumatology International Trials Organisation, will allow to improve detection and treatment of JIA.

The presentation of this clinical cases and the discussion may be useful for understanding the disease cause and will help to differentiate sJIA and MAS from other disorders, and to improve treatment outcomes.
\end{abstract}

Key words: diagnosis, macrophage activation syndrome, systemic juvenile idiopathic arthritis.

\section{Introduction}

Juvenile idiopathic arthritis (JIA) is a common rheumatic disease of childhood that frequently leads to disability [1, 2]. Systemic juvenile idiopathic arthritis (sJIA), also known as Still's disease, is one of the most severe subtypes of JIA [3]. According to International League of Associations for Rheumatology (ILAR) criteria, diagnosis of SIIA requires the presence of arthritis in one or more joints with a documented fever of at least 2 weeks duration, and accompanied by one or more of the following: erythematous rash, lymph nodes enlargement, hepatomegaly and/or splenomegaly, serositis [4].

Systemic JIA is a heterogeneous subtype of arthritis [5]. It develops in 10-20\% of all JIA cases [1]. Systemic arthritis differs from the other categories of JIA and is characterized by an autoinflammatory fenotype [1-3]. Fever may be the main manifestation in the onset of the disease and it may frequently get misdiagnosed as a bacterial or viral infection, malignancy, or another systemic disease $[1,6]$. The diagnosis is previously based on clinical data [1, 3].

The pathogenesis of SJIA is not completely clear [7]. Inflammatory cytokines interleukin 6 (IL-6), IL-1, tumor necrosis factor $\alpha$ (TNF- $\alpha$ ) and activation of inflammasomes play a main role $[5,7]$.

The most dangerous complication of sJIA is the macrophage activation syndrome (MAS). This potentially life-threatening condition develops in $10-50 \%$ of sJIA patients $[3,8]$. Frequently, it is very difficult to distinguish MAS from the other complications $[1,3,8]$.

\section{Objective and methods}

The objective of this article is to present the clinical variability of sJIA.

Methods: case study presentation as a basis for discussion, literature search of MEDLINE, and Scopus atabase, American College of Rheumatology (ACR), European League Against Rheumatism (EULAR), and Paediatric 
Rheumatology International Trials Organisation (PRINTO), particularly in the subject of systemic IIA, using the combination of words "systemic juvenile idiopathic arthritis" and "clinical course", "diagnosis", "complication", "macrophage activation syndrome"; discussion of the problem based on the clinical case and cited articles.

We used relevant full-text articles in English which were published between January 2012 and March 2020. We also used some basic articles that contain classification or diagnostic approaches which were published in 2004-2008.

Studies with results relating to the clinical presentation, diagnosis and macrophage activation syndrome in patients with SJIA were selected for analysis. The exclusion criteria were the language of the article other than English and lack of access to the full text.

\section{Results}

The authors present the cases of four patients (three girls and one boy) with sIIA. We have followed-up the first of these patients for 4 years, the rest - for over the last 2 years. In all of these cases the diagnosis was based on ILAR criteria (Table I). Informed consent was obtained from all patients and/or their parents.

\section{Case 1}

A 3-year-old boy was admitted to the city children's hospital with complaints of fever up to $40.5^{\circ} \mathrm{C}$, single vomiting and limping on the right leg. The first symp- toms were reported 7 days before the admission. They included temperature rise of up to $38.5^{\circ} \mathrm{C}$ and a single macular spot on the right shin. Four days later the boy started limping on his right leg. There was an increase in his body temperature up to $40^{\circ} \mathrm{C}$ every day.

He was born after a first full-term pregnancy, complicated by dysfunction of the placenta and polyhydramnios via spontaneous vaginal delivery, weight 2900 g. The delay in psychomotor development occurred: he started balancing his head at 6 months, sitting at 10 months, walking at 20 months.

Taking into account high temperature and vomiting, acute meningitis was suspected at the time of his hospital admission. Laboratory testing revealed anemia - hemoglobin ( $\mathrm{Hb}) 10.2 \mathrm{~g} / \mathrm{dl}$, leukocytosis 25,600/ $\mathrm{\mu l}$, an erythrocyte sedimentation rate (ESR) of $28 \mathrm{~mm} / \mathrm{h}$, C-reactive protein (CRP) $26.8 \mathrm{mg} / \mathrm{dl}$, anti-streptolysin O (ASO) level of $200 \mathrm{IU}$ (reference value < $150 \mathrm{IU}$ ) (Table II). Ferritin level was normal $289.7 \mathrm{ng} / \mathrm{ml}$. Spinal puncture with cerebrospinal fluid analysis allowed to rule out meningitis. Upon the results of lab tests, antibiotic therapy was prescribed.

A day later a few other symptoms appeared. The boy got erythematous macular rash on the back, chest and around the right elbow and there was the swelling of the right ankle. Acute rheumatic fever (ARF) was also considered, taking into account fever, transient arthritis and the results of laboratory tests.

However, the patient's age, lack of data for previous streptococcal infection and ineffectiveness of antibacte-

Table I. Clinical features and treatment of reported patients

\begin{tabular}{|c|c|c|c|c|}
\hline Feature & Case 1 & Case 2 & Case 3 & Case 4 \\
\hline Gender & Male & Female & Female & Female \\
\hline Age, years & 3 & 6 & 12 & 1 year 4 months \\
\hline Quotidian fever & Yes & Yes & Yes & Yes \\
\hline Typical evanescent rash & Yes & Yes & No & Yes \\
\hline Hepatomegaly & Yes & Yes & Yes & Yes \\
\hline Splenomegaly & Yes & No & Yes $^{\star}$ & Yes $^{*}$ \\
\hline Lymphadenopathy & Yes & Yes & Yes* $^{*}$ & Yes \\
\hline Pericarditis & Yes $^{*}$ & Yes & Yes* & No \\
\hline Pleuritis & No & Yes & No & No \\
\hline Abdominal pain & Yes & No & No & No \\
\hline Arthritis & Yes & Yes & Yes* $^{*}$ & No \\
\hline Arthralgia & Yes & Yes & Yes & Yes \\
\hline MAS & Yes & No & No & No \\
\hline $\begin{array}{l}\text { Treatment to achieve } \\
\text { remission }\end{array}$ & MPS IV, MPS PO & $\begin{array}{c}\text { MPS IV pulse, MPS PO, } \\
\text { MTX, tocilizumab }\end{array}$ & MPS PO, MTX & MPS IV, MPS PO \\
\hline Flares & Yes & Yes & No & Yes \\
\hline
\end{tabular}

MPS IV - methylprednisolone intravenous, MPS PO - methylprednisolone per os, MTX-methotrexate. *Signs were revealed by instrumental examination. 
Table II. Laboratory findings of reported patients

\begin{tabular}{|c|c|c|c|c|c|}
\hline Parameter & Case 1 & Case 2 & Case 3 & Case 4 & Reference range \\
\hline Leucocytes, cells/ul & 25,600 & 63,600 & 30,620 & 50,840 & $3,500-10,000$ \\
\hline Platelets, cells $/ \mu \mathrm{l}$ & 276,000 & 674,100 & 412,100 & 594,000 & $150,000-390,000$ \\
\hline $\mathrm{ESR}, \mathrm{mm} / \mathrm{h}$ & 28 & 64 & 58 & 35 & $<15$ \\
\hline CRP, mg/dl & 26,8 & 277.25 & 141.5 & 115.7 & $<5$ \\
\hline Ferritin, ng/ml & 1389 & 325.6 & 953 & na & $13-150$ \\
\hline LDG, U/I & 794 & 479.4 & 353.9 & 1187 & $120-300$ \\
\hline $\mathrm{RF}, \mathrm{IU} / \mathrm{ml}$ & neg & neg & doubtful & neg & $<14$ \\
\hline ACPA, U/ml & na & na & $<7$ & na & $<20$ \\
\hline ANA, titer & $1: 80$ & $<1: 100$ & $<1: 100$ & $<1: 100$ & $<1: 100$ \\
\hline Serum calprotectin, $\mu \mathrm{g} / \mathrm{ml}$ & 15 & na & 24 & 92.6 & $<2.9$ \\
\hline
\end{tabular}

ANA - antinuclear antibodies, CRP-C-reactive protein, ESR - erythrocyte sedimentation rate, $L D G$ - lactate dehydrogenase, $R F$-rheumatoid factor. In the table the highest levels of parameters are presented: na - not available, doubtful $-14.2 \mathrm{IU} / \mathrm{ml}$ in the first test, all other determinations $<10 \mathrm{IU} / \mathrm{ml}$

rial therapy rejected this diagnosis. Immunoglobulin $M$ to the measles and rubella were also negative. Therefore, the rash was considered as a medication allergic reaction and intravenous prednisolone was prescribed for 5 days, then the patient took oral prednisolone in the dose $1 \mathrm{mg} / \mathrm{kg} /$ day, and the intensity of rash decreased.

Despite the treatment the patient continued to be febrile once a day, but not every day, and a transient abdominal pain occurred; therefore, leukemia was decided to be excluded. After nine days of the glucocorticoid treatment, prednisolone was rapidly interrupted for one day and bone marrow puncture was performed. Bone marrow test was normal.

On the second day after prednisolone interruption, generalized tonic-clonic seizures with a loss of consciousness and coma over the next 3 days developed. Laboratory testing detected leukocytosis 14,600/ $\mu$, anemia $(\mathrm{Hb})-9.1 \mathrm{~g} / \mathrm{dl}$, increased levels of lactate dehydrogenase (LDG) - $646.0 \mathrm{U} / \mathrm{l}$, alanine aminotransferase $(\mathrm{ALT})-68 \mathrm{U} / \mathrm{l}$ (reference $<37 \mathrm{U} / \mathrm{l}$ ), aspartate aminotransferase (AST) - $58 \mathrm{U} / \mathrm{l}$ (reference < $40 \mathrm{U} / \mathrm{l}$ ), and ferritin (1389 $\mathrm{ng} / \mathrm{ml}$ ), fibrinogen level was $3.13 \mathrm{~g} / \mathrm{l}$ (reference 2-4 g/l). Bilirubin and electrolytes were normal. Acute encephalitis was also suspected. Herpes simplex virus (HSV), cytomegalovirus (CMV), Epstein-Barr virus (EBV) and Lyme borreliosis were ruled out.

A cranial computerized tomography (CT) scan revealed cerebral edema, purulent otitis media, and cortical atrophy. Lincomycin (due to purulent otitis media), intravenous methylprednisolone (10 $\mathrm{mg} / \mathrm{kg} /$ day for 5 days), and intravenous immunoglobulins $1 \mathrm{~g} / \mathrm{kg}$ were prescribed. On the background of the pulse therapy the temperature normalized, the rash disappeared.

The patient was referred to the neurological department of the regional hospital due to seizures and suspected encephalitis. He was presented with enlarged cervical lymph nodes, transient elbow swelling, hepatosplenomegaly, tachycardia and severe sluggishness. Thickened layers of the pericardium was detected on the thoracic CT. Neurological symptoms as movement limitation at the left forearm and hand, speech problems were observed, and they were slowly resolved.

Oral methylprednisolone in the dose of $1 \mathrm{mg} / \mathrm{kg}$ was continued. The attempts to reduce the corticosteroid doses were accompanied by the appearance of fever, macular rash on the trunk and extremities and joint pain. Rheumatoid factor (RF) and antinuclear antibodies (ANA) were negative (Table II). Antinuclear antibodies-screen for the most often systemic inflammatory connective tissue diseases and human leukocyte antigen (HLA) B27 were negative.

Taking into account quotidian fever, transient erythematous rash, lymphadenopathy, arthritis and arthralgia, hepatosplenomegaly, serositis SJIA was diagnosed (Table I). Oral methylprednisolone in the dose of $1 \mathrm{mg} / \mathrm{kg} /$ day was prescribed. Neurological symptoms were suggested as encephalopathy on the background of autoimmune disease, but encephalitis was not completely excluded.

Further examination revealed a significant increase of ALT $1842 \mathrm{U} / \mathrm{l}$, and AST $1310 \mathrm{U} / \mathrm{l}$ and decrease of fibrinogen level to $2.2 \mathrm{~g} / \mathrm{l}$. The bilirubin level was within normal range.

Enzyme-linked immunosorbent assay and polymerase chain reaction excluded viral etiology of hepatitis. Increased levels of thallium and arsenic were found in blood and hair samples, which suggested poisoning. However, we couldn't detect the causes of the poisoning, and these microelements were normal in all family members.

On the background of glucocorticoid therapy during the next 6 months patient's general condition improved, all symptoms of JIA disappeared and methylpredniso- 
lone was discontinued. However, generalized tonic-clonic seizures recurred 3-4 times a month. Symptomatic epilepsy was diagnosed and valproic acid was prescribed.

After eight months of remission, the boy's condition again worsened. He was admitted to the regional children's hospital with complaints of fever up to $38^{\circ} \mathrm{C}$, joint pain, abdominal pain and sluggishness. The boy was sick for the last one day. Further unstable macular rash on the trunk and extremities, limping on the left leg, transient arthritis of both knees and right ankle developed.

Laboratory testing estimated slight leukocytosis $9,700 / \mu \mathrm{l}$, ESR of $10 \mathrm{~mm} / \mathrm{h}$, CRP $21.56 \mathrm{mg} / \mathrm{dl}$, significantly increased ferritin level $1645 \mathrm{ng} / \mathrm{ml}$. Increased value of ALT $167 \mathrm{U} / \mathrm{I}$ and AST $104 \mathrm{U} / \mathrm{I}$ was detected.

Ultrasound examination of both knees confirmed bilateral synovitis. Thallium and arsenic levels in blood and hair samples were normal. Oral methylprednisolone was prescribed in the dose of $1 \mathrm{mg} / \mathrm{kg} /$ day for 2 months with the further gradual dose reduction. The symptoms of JIA did not recur for the next 2 years after this therapy.

The patient demonstrates a decrease in cognitive functions, hyperactivity, and euphoria. He continues valproic acid intake due to his epilepsy. Taking into account unusual course of SIIA on the background of neurological changes, we suggested a genetic pathology. Whole exome sequencing found the mutation in ATP6VOA1 gene that can be contributed to his neurological condition and need to be experimentally validated.

\section{Case 2}

A 6-year-old girl was admitted to the regional children's hospital because of having a fever for 2 weeks. A fever was accompanied by erythematous macular rash, cervical, thoracic spine pain, left wrist and right ankle swelling.

From the history it is known that arthralgia and spine pain developed a few months before the hospital admission. Two weeks before the admission a fever appeared and spine pain became more severe, the erythematous rash occurred on the peaks of fever and disappeared within a few hours when the fever decreased. The patient was treated in the infectious disease department by antibiotics without effect.

Physical examination revealed cervical lymphadenopathy, an enlarged liver $(+2 \mathrm{~cm})$, tachycardia, swollen and painful left and right knees, left wrist and right ankle. Laboratory testing revealed leukocytosis 15,300-63,600/ $\mu \mathrm{l}$, an ESR of 20-25 mm/h, CRP (98.1$139.8 \mathrm{mg} / \mathrm{dl})$. Rheumatoid factor and ANA were negative. Serum level of creatine kinase (CK) was normal, LDG (369.0-479.4 U/I) (Table II).

Ultrasound examination revealed the signs of left hip, left and wright knee bursitis and synovitis, left wrist synovitis. Chest X-ray was normal. Antinuclear antibodies-screen for the most often systemic inflammatory connective tissue diseases and HLA-B27 were negative. Taking into account fever that the patient was having for more than 2 weeks, arthritis, typical rash, cervical lymphadenopathy, hepatomegaly, sJIA was diagnosed. Methylprednisolone was administered intravenous for 5 days, than - oral in the dose of $1.0 \mathrm{mg} / \mathrm{kg} /$ day. This dose didn't control a fever; therefore, it was increased to $1.5 \mathrm{mg} / \mathrm{kg} /$ day.

The patient's condition became better, body temperature was normal for 4 days, the rash was not observed. On the 17th day of corticosteroid treatment the child became ill with measles and the fever occurred again. The patient was treated in the infectious disease department for 7 days. The dose of methylprednisolone was reduced. The patient continued to have fever; therefore, she was referred to rheumatology department.

Laboratory examination revealed leukocytosis 26,240/ $\mu$ l, an ESR of $64 \mathrm{~mm} / \mathrm{h}, \mathrm{CRP} 277.25 \mathrm{mg} / \mathrm{dl}$, thrombocytosis 492,100/ $\mu$ l. The onco-hematological diseases were ruled out as the bone marrow and abdominal CT was normal. The patient condition deteriorated: a fever increased to $>39^{\circ} \mathrm{C}$, severe arthralgias, myalgias and dyspnea developed.

Leukocytosis and thrombocytosis increased up to $51,000 / \mu \mathrm{l}$ and $674,100 / \mu \mathrm{l}$ respectively, an ESR was $30 \mathrm{~mm} / \mathrm{h}$, CRP $-26,5 \mathrm{mg} / \mathrm{dl}$. Ferritin level increased (Table II) and procalcitonin test was normal.

The signs of pericarditis were revealed by echocardiography, pleuritis - on the chest $X$-ray. Pulse intravenous methylprednisolone therapy was administered for 3 days, then oral methylprednisolone $2 \mathrm{mg} / \mathrm{kg} / \mathrm{day}$ and subcutaneous methotrexate $15 \mathrm{mg} / \mathrm{m}^{2}$ were added.

The patient's condition gradually became better. But the attempts to reduce the dose of methylprednisolone to maintenance (6-8 $\mathrm{mg} /$ day) provoked an exacerbation. Currently the patient has started intravenous tocilizumab intake ( $8 \mathrm{mg} / \mathrm{kg} / 2$ weeks) and methylprednisolone is being gradually discontinued.

\section{Case 3}

A 12-year-old girl was admitted to the infectious disease department of our hospital because of a fever of unknown origin, headache, and migratory arthralgia in elbow and knee joints, morning stiffness about 15 minutes. The symptoms developed 6 days before the admission with febrile fever and headache, in 5 days arthralgia joined.

Physical examination revealed slightly painful left elbow and both knee joints without swelling. Lung and heart sounds were normal. Mild hepatosplenomegaly was found. Taking into account neutrophilic leukocyto- 
sis $14,600 / \mu \mathrm{l}, 80 \%(11,168 / \mu \mathrm{l})$ of neutrophils, antibiotic treatment was prescribed. Despite this treatment, the fever continued with the temperature rise up to $39^{\circ} \mathrm{C}$.

The results of laboratory testing showed an incre-

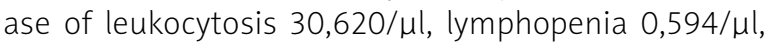
ESR of $58 \mathrm{~mm} / \mathrm{h}$, anemia - Hb $11.0 \mathrm{~g} / \mathrm{dl}$, increased levels of CRP, ferritin, LDG (Table II), ASO $1258 \mathrm{IU} / \mathrm{ml}$ (reference $<150 \mathrm{lU} / \mathrm{ml}$ ).

Procalcytonin serum concentration was normal. Herpes simplex virus, CMV, EBV, toxoplasma, mycoplasma, chlamydia, ureaplasma, hepatitis B and C viruses infectious were ruled out. Antinuclear antibodies and ANA-screen for the most often systemic inflammatory connective tissue diseases were negative. Rheumatoid factor was doubtful (14.2 IU/ml - reference up to $14.0 \mathrm{IU} /$ $\mathrm{ml})$, but anticyclic citrullinated peptide (ACPA ) was normal. Rheumatoid factor after 3 months was also normalized. Blood calprotectin level was 24 mg/ml (Table II).

Taking into account fever, arthralgia, hepatosplenomegalia and the results of laboratory tests oncohematological diseases were considered to be excluded. The bone marrow was normal, chest and abdominal CT confirmed hepatosplenomegaly and revealed pericarditis and lymphadenopathy. Ultrasound examination revealed the signs of left elbow synovitis and left knee bursitis and synovitis.

Taking into consideration fever that the patient was having for 2 weeks, arthritis, hepatosplenomegaly and serositis, systemic JIA was diagnosed. Oral methylprednisolone $1 \mathrm{mg} / \mathrm{kg} /$ day and subcutaneous methotrexate $15 \mathrm{mg} / \mathrm{m}^{2} /$ week were prescribed. The patient responded to the treatment. In six weeks the full dose of the methylprednisolone was reduced, and in 9 months it was completely discontinued. Currently the patient is in remission and continues taking methotrexate.

\section{Case 4}

A 16-month-old girl was referred from the infectious disease department on the 15th day from the disease onset because of fever and ineffective antibacterial therapy. Child's mother complained of body temperature that was increasing to more than $39^{\circ} \mathrm{C}$ once or twice a day (in the morning and in the evening) and was returning back to normal between fever peaks that were accompanied by an erythematous macular rash. The rash appeared on the trunk, extremities and buttocks and it increased at the peak of temperature. Physical examination revealed a few hyperpigmented lesions ("coffe-with-milk spots") on the child's skin, a typical macular rash, joint hypermobility, slightly enlarged liver and cervical lymph nodes. There were no signs of arthritis.

The laboratory values were significant for leukocytes, ESR, platelets, CRP and LDG (Table II). Anemia was revealed $\mathrm{Hb} 9.7 \mathrm{~g} / \mathrm{dl}$, and procalcitonin test was normal. Antinuclear antibodies and RF were negative. Antinuclear antibodies-screen for the most often systemic inflammatory connective tissue diseases was also negative. Blood calprotectin level was $92.6 \mathrm{\mu g} / \mathrm{ml}$. The abdominal ultrasound examination revealed hepatosplenomegaly.

Oral methylprednisolone $1 \mathrm{mg} / \mathrm{kg} /$ day was prescribed according to the circadian rhythm, but fever continued to rise once a day at night; therefore, the dose was increased to $1.5 \mathrm{mg} / \mathrm{kg} /$ day and it was given in 4 divided doses throughout the whole day. This allowed to achieve the remission.

During the 10 months of follow-up, there was only one flare on the background of a viral infection (4 months after the therapy started, in a dose of methylprednisolone $4 \mathrm{mg} /$ day), which was accompanied by fever, rash and arthralgia and required to increase the glucocorticoid doses to $1 \mathrm{mg} / \mathrm{kg} /$ day for one week and then again gradually reduce to $4 \mathrm{mg} /$ day. Currently this dose is enough to control fever and inflammation.

\section{Discussion}

Herein authors present four cases of SJIA. Each of these cases is interesting and unique. Clinical features of the reported cases are shown in Table I. Three out of four presented patients were female, however, other researchers reported that SIIA develops equally often in both sexes $[1,9,10]$. The age at the onset of the disease in our study ranged from 1 to 12 years. The data of the Childhood Arthritis and Rheumatology Research Alliance (CARRA) Legacy Registry noted that mean age of SJIA onset was 4.6 years and ranged from 2.3 to 9.4 years [9]. Other studies showed the similar age of disease onset $[10,11]$.

High fever was the first and the main symptom in all cases. All patients were previously referred to the infectious disease department and were treated by antibiotics. Nonspecific onset of SJIA, which can be misdiagnose with infectious diseases (bacterial or viral), is also outlined by the other researchers [1].

As SJIA is a clinical diagnosis of exclusion, others systemic inflammatory connective tissue diseases as well as ARF were also ruled out. Therefore, it required a large number of additional laboratory testing. Acute rheumatic fever was suspected in the first reported patient; however, the lack of evidence of preceding group A streptococcal infection allowed to exclude this diagnosis $[12,13]$. The sJIA diagnostics also demand to rule out malignancy [1]. It is very important before the start of systemic corticosteroid treatment.

The most difficult way to the diagnosis was in the first case. The patient developed seizures and coma on the onset of the disease. Encephalopathy as MAS 
clinical manifestation is described in many studies [14, $16,17]$. Central nervous system involvement was observed in 33-40\% of MAS cases [14, 15, 17]. Lethargy and seizures were the most frequent among neurological signs of MAS, therefore, coma was observed only in $1.7 \%$ of cases [14]. Irritability, confusion, mood changes are also reported [14]. Other clinical and laboratory manifestations of MAS include continuous fever, pancytopenia, hyperferritinemia, fibrinolytic coagulopathy, and liver dysfunction $[16,18]$.

A reported patient was presented with central nervous system dysfunction, and he also met one laboratory MAS criteria, according to the preliminary diagnostic guidelines for MAS in patients with sJIA [19]: platelet count 176,000/ $\mu$ l (Table III).

However, leucocytes, AST and fibrinogen levels didn't respond MAS criteria [19]. Despite the absence of leucopenia, we observed the decrease of leucocytes number from $25,000 / \mu \mathrm{l}$ to $14,600 / \mu \mathrm{l}$ and even to $4,900 / \mu \mathrm{l}$, erythrocytes number from 4,15 to 3,68 million per microliter, and hemoglobin level from $10.2 \mathrm{~g} / \mathrm{dl}$ to $9.1 \mathrm{~g} / \mathrm{dl}$.

According to the 2016 classification criteria for MAS in patients with sJIA this complication can be diagnosed in a febrile patient with known or suspected JIA if the following criteria are met: ferritin level $>684 \mathrm{ng} / \mathrm{ml}$; plus any two of the following: platelets $\leq 180,000 / \mu \mathrm{l}$, AST $>48 \mathrm{U} /$, triglycerides $>156 \mathrm{mg} / \mathrm{dl}$, fibrinogen $\leq 360 \mathrm{mg} / \mathrm{dl}$ [13].

So, when the signs of nervous system involvement developed in a reported patient, his ferritin level, AST and fibrinogen values also met 2016 MAS criteria (Table III). In dynamics fibrinogen even decreased to $220 \mathrm{mg} / \mathrm{dl}$, and AST level significantly increased. Therefore, retrospectively we can conclude that the patient developed MAS.

Macrophage activation syndrome may often be triggered by the medications, including biologic, an infection, or a change in therapy [14, 20, 21]. However, the researchers outline that this complication also develops without triggers, on the background of active sIIA [14]. In our first case a rapid corticosteroid discontinuation and infection (purulent otitis) could lead to the development of MAS.

The innate immune system, especially monocytes/ macrophages, neutrophils and natural killer cells (NK-cells), plays a central role in the initiation of MAS [3, 8, 17]. Many researchers suggest that pathophysiology of MAS is based on a defect in lymphocyte cytolytic activity $[17,18]$. On the other hand, cytotoxic T-lymphocyes (CD8 T-cells), as the representatives of adaptive immunity, are also involved in pathogenesis of MAS [18].

A great importance is also given to the genetic predisposition to the overactive macrophage response and to the genetic defects in the cytolytic pathway [8, 16-18]. Therefore, genetic predisposition and possible triggers on the background of active inflammation cause an increasing of macrophages and T-lymphocytes activity, leading to cytokine storm, which can result in tissue damage, multi-organ dysfunction and even death [18, 22].

In the case 2 we also observed deterioration of patient's condition after measles and the reduction of corticosteroid dose. The child was presented with sig-

Table III. Comparison of the classification criteria for macrophage activation syndrome 2005 and 2016 with symptoms developed in a reported case 1

\begin{tabular}{|c|c|c|c|}
\hline Criterion & $2005[18]$ & 2016 [13] & Case 1 \\
\hline \multicolumn{4}{|l|}{ Laboratory criteria } \\
\hline Ferritin, ng/ml & - & $>684$ & 1389 \\
\hline Platelets, cells $/ \mu \mathrm{l}$ & $\leq 262,000$ & $\leq 180,000$ & 176,000 \\
\hline $\mathrm{AST}, \mathrm{U} / \mathrm{I}$ & $>59$ & $>48$ & 58 \\
\hline Triglycerides, mg/dl & - & $>156$ & 139 \\
\hline Fibrinogen, mg/dl & $\leq 250$ & $\leq 360$ & 313 \\
\hline Leucopenia, cells/ $\mu$ l & $\leq 4,000$ & - & $14,600-4,900$ \\
\hline \multicolumn{4}{|l|}{ Clinical criteria } \\
\hline $\begin{array}{l}\text { Central nervous system } \\
\text { dysfunction }\end{array}$ & Seizures, irritability coma, lethargy & - & $\begin{array}{l}\text { Seizures, coma, } \\
\text { mood changes }\end{array}$ \\
\hline Hemorrhages & Purpura, bruising, bleeding & - & - \\
\hline Hepatomegaly & $>3 \mathrm{~cm}$ & - & $2 \mathrm{~cm}$ \\
\hline $\begin{array}{l}\text { Histopathological } \\
\text { criteria }\end{array}$ & $\begin{array}{l}\text { Macrophages hemophagocytosis } \\
\text { in the bone marrow }\end{array}$ & - & na \\
\hline Diagnosis & $\begin{array}{c}\text { Two or more laboratory criteria; } \\
\text { any 2, 3, or more clinical and/or } \\
\text { laboratory criteria }\end{array}$ & $\begin{array}{c}\text { A febrile patient with known or sus- } \\
\text { pected JIA plus ferritin, plus any two } \\
\text { other laboratory criteria }\end{array}$ & \\
\hline
\end{tabular}


nificant leukocytosis and thrombocytosis, however, ESR decreased from 64 to $30 \mathrm{~mm} / \mathrm{h}$, and CRP - from 277.25 to $26,5 \mathrm{mg} / \mathrm{dl}$.

There were no signs of liver disfunction and fibrinolytic coagulopathy. Ferritin level didn't also meet MAS criteria. The serositis (pleuritis and pericarditis) were developed and caused the worsening of patient's condition. In this case viral infection and the reduction of corticosteroid dose induced the disease flare. Only in this case the disease was poorly controlled with corticosteroid and methotrexate treatment, therefore biological therapy was started.

The case 3 differs from the others ones by the patient's age that isn't common for sJIA, and the onset of the disease was with arthritis, but without typical rash. Evanescent rash occurred in $81 \%$ of patients with sJIA [23]. Splenomegaly, enlarged thorax and abdominal lymph nodes, pericarditis and arthritis were detected only by ultrasound or radiological methods. The girl demonstrated a significant increase of ESR and ferritin level. This is a single patient among the reported ones without the flare for the following period.

The last presented patient was the youngest. Such a young age is not the only peculiarity of this case, though. Another specific feature is the presence of the signs of heritable disorders of connective tissue, which are frequently associated with inflammatory connective tissue diseases [24]. A hyperpigmented sports could indicate some genetic problems, as they were also observed in child's father [25].

On the other hand, currently there is no enough evidence for genetic testing. This child demonstrated a significant level of serum calprotectin and LDG. Serum calprotectin is considered as a new inflammation marker in paediatric rheumatic diseases, especially in patients with sJIA, and as a predictor of flare and treatment control $[26,27]$.

In summary, the course of SJIA is very variable and, therefore, its recognition may be delayed. As sJIA is a diagnosis of exclusion [28], it requires ruling out other diseases with similar symptoms. Systemic juvenile idiopathic arthritis diagnosis is based on clinical criteria, however, additional methods (ultrasound and/or radiological) are often required to detect typical for sJIA features. It is very important to exclude malignancy before corticosteroid treatment to avoid mistakes and hard complication. The presence of other genetic pathology or predisposition can also lead to a misdiagnosis or to the diagnostic delay.

Moreover, sJIA can be complicated by the life-threatening disorders which are also difficult to be diagnosed in time and to be differentiated from the essential systemic inflammation. Using the 2016 classification criteria for MAS diagnostic allowed to consider MAS in the diagnostically challenging cases, which confirms their sensitivity in pediatric patients [29].

Taking into account the heterogenesity of some groups of JIA, PRINTO initiated to reconsider the classification of JIA, and S IIA in particular $[2,29]$. There is the category of patients with sJIA that doesn't present with arthritis at the onset of the disease, as well as adult onset Still disease. One of the presented here patients also did not meet the signs of arthritis. The modification of JIA criteria will allow to improve their detection and treatment [30, 31].

\section{Conclusions}

The clinical cause of systemic JIA is very variable, which results in difficulties of disease recognition and requires exclusion of infections, malignancies and other inflammatory diseases.

In this literature review based on case series we outline main challenges in diagnostic of systemic JIA and macrophage activation syndrome. The reviewed literature showed last updates for the improvement of classification, diagnostic of systemic JIA and its complication.

Presentation of this clinical cases and discussion may be very useful for understanding the disease cause and will help to differentiate systemic JIA and MAS from other disorders and improve treatment outcomes.

The authors declare no conflict of interest.

\section{References}

1. Cassidy JT, Petty RE. Chronic arthritis in childhood. In: Textbook of Pediatric Rheumatology, Cassidy JT, Petty RE, Laxer RM, Lindsley CB (eds.). Saunders Elesvier, Philadelphia 2005: 206-300.

2. Martini A, Ravelli A, Avcin T, et al. Toward new classification criteria for juvenile idiopathic arthritis: first steps, Pediatric Rheumatology International Trials Organization international consensus. J Rheumatol 2019; 46: 190-197, DOI: 10.3899/ jrheum.180168.

3. Vandenhaute J, Wouters $\mathrm{CH}$, Matthys P. Natural killer cells in systemic autoinflammatory diseases: a focus on systemic juvenile idiopathic arthritis and macrophage activation syndrome. Front Immunol 2020; 10: 3089, DOI: 10.3389/fimmu. 2019.03089.

4. Petty RE, Southwood TR, Manners P, et al. International League of Associations for Rheumatology classification of juvenile idiopathic arthritis: second revision, Edmonton 2001. J Rheumatol 2004; 31: 390-392.

5. Woo P. Systemic juvenile idiopathic arthritis: diagnosis, management, and outcome. Nat Clin Pract Rheumatol 2006; 2: 2834, DOI: 10.1038/ncprheum0084.

6. Komorovsky RR, Boyarchuk OR, Synytska VO. Streptococcus gordonii-associated infective endocarditis in a girl with Bar- 
low's mitral valve disease. Cardiol Young 2019; 29: 1099-1100, DOI: 10.1017/S1047951119001434.

7. Pardeo M, Bracaglia C, De Benedetti F. Systemic juvenile idiopathic arthritis: new insights into pathogenesis and cytokine directed therapies. Best Pract Res Clin Rheumatol 2017; 31 505-516, DOI: 10.1016/j.berh.2018.02.002.

8. Ravelli A, Grom AA, Behrens EM, Cron RQ. Macrophage activation syndrome as part of systemic juvenile idiopathic arthritis: diagnosis, genetics, pathophysiology and treatment. Genes Immun 2012; 13: 289-298, DOI: 10.1038/gene.2012.3.

9. Janow G, Schanberg LE, Setoguchi S. The systemic juvenile idiopathic arthritis cohort of the Childhood Arthritis and Rheumatology Research Alliance Registry: 2010-2013. J Rheumatol 2016; 43: 1755-1762, DOI: 10.3899/jrheum.150997.

10. Soponkanaporn S, Jaovisidha S, Vilaiyuk S. Long-term outcomes and predictors of biologic treatment in systemic juvenile idiopathic arthritis in a single-center experience in Thailand. Indian J Rheumatol 2018; 13: 26-32, DOI: 10.4103/injr.injr_83_17.

11. Russo RA, Katsicas MM. Patients with very early-onset systemic juvenile idiopathic arthritis exhibit more inflammatory features and a worse outcome. J Rheumatol 2013; 40: 329334, DOI: 10.3899/jrheum.120386.

12. Boyarchuk O, Hariyan T, Kovalchuk T. Clinical features of rheumatic heart disease in children and adults in Western Ukraine. Bangladesh J Med Sci 2019; 18: 87-93, DOI: 10.3329/bjms.v18i1.39556.

13. Boyarchuk O, Boytsanyuk S, Hariyan T. Acute rheumatic fever: clinical profile in children in western Ukraine. J Med Life 2017; 10: 122-126.

14. Minoia F, Davì S, Horne A, et al. Clinical features, treatment, and outcome of macrophage activation syndrome complicating systemic juvenile idiopathic arthritis: a multinational, multicenter study of 362 patients. Arthritis Rheumatol, 2014; 66: 3160-3169, DOI: 10.1002/art.38802.

15. Ravelli A, Minoia F, Davì S, et al. 2016 Classification criteria for macrophage activation syndrome complicating systemic juvenile idiopathic arthritis: a European League Against Rheumatism/American College of Rheumatology/Paediatric Rheumatology International Trials Organisation collaborative initiative. Arthritis Rheumatol 2016; 68: 566-576, DOI: 10.1002/art.39332.

16. Grom AA, Ilowite NT, Pascual V, et al. Rate and clinical presentation of macrophage activation syndrome in patients with systemic juvenile idiopathic arthritis treated with canakinumab Arthritis Rheumatol 2016; 68: 218-228, DOI: 10.1002/art.39407.

17. Vastert SJ, van Wijk R, D'Urbano LE, et al. Mutations in the perforin gene can be linked to macrophage activation syndrome in patients with systemic onset juvenile idiopathic arthritis. Rheumatology 2010; 49: 441-449, DOI: 10.1093/rheumatology/ kep418.
18. Crayne CB, Albeituni S, Nichols KE, Cron RQ. The immunology of macrophage activation syndrome. Front Immunol 2019; 10: 119, DOI: 10.3389/fimmu.2019.00119.

19. Ravelli A, Magni-Manzoni S, Pistorio A, et al. Preliminary diagnostic guidelines for macrophage activation syndrome complicating systemic juvenile idiopathic arthritis. J Pediatr 2005; 146: 598-604, DOI: 10.1016/j.jpeds.2004.12.016.

20. Ruperto N, Brunner HI, Quartier P, et al. Two randomized trials of canakinumab in systemic juvenile idiopathic arthritis. N Engl J Med 2012; 367: 2396-2406, DOI: 10.1056/NEJMoa1205099.

21. Buoncompagni A, Loy A, Sala I, Ravelli A. The paradox of macrophage activation syndrome triggered by biologic medications. Pediatr Rhematol Online J 2005; 3: 70-73.

22. Canna SW, Behrens EM. Making sense of the cytokine storm: a conceptual framework for understanding, diagnosing and treating hemophagocytic syndromes. Pediatr Clin North Am 2012; 59: 329-344, DOI: 10.1016/j.pcl.2012.03.002.

23. Behrens EM, Beukelman T, Gallo L, et al. Evaluation of the presentation of systemic onset juvenile rheumatoid arthritis: data from the Pennsylvania Systemic Onset Juvenile Arthritis Registry (PASOJAR). J Rheumatol 2008; 35: 343-348.

24. Boyarchuk O. Features of heritable disorders of connective tissue in children with acute rheumatic fever and rheumatic heart disease. Reumatologia 2020; 58: 21-25, DOI: 10.5114/ reum.2020.93509.

25. Florez H, Peris P, Guañabens N. Fibrous dysplasia. Clinical review and therapeutic management. Med Clin (Barc) 2016; 147: 547-553, DOI: 10.1016/j.medcli.2016.07.030.

26. Mariani A, Marsili M, Nozzi M, et al. Serum calprotectin: review of its usefulness and validity in paediatric rheumatic diseases. Clin Exp Rheumatol 2015; 33: 109-114.

27. Bojko J. Measurement of blood calprotectin (MRP-8/MRP-14) levels in patients with juvenile idiopathic arthritis. Reumatologia 2017; 55: 10-14, DOI: 10.5114/reum.2017.66682.

28. Tada Y, Inokuchi S, Maruyama A, et al. Are the 2016 EULAR/ ACR/PRINTO classification criteria for macrophage activation syndrome applicable to patients with adult-onset Still's disease? Rheumatol Int 2019; 39: 97-104, DOI: 10.1007/s00296018-4114-1.

29. Martini A. It is time to rethink juvenile idiopathic arthritis classification and nomenclature. Ann Rheum Dis 2012; 71: 14371439, DOI: 10.1136/annrheumdis-2012-201388.

30. Rumsey DG, Laxer RM. The challenges and opportunities of classifying childhood arthritis. Curr Rheumatol Rep 2020; 22: 4, DOI: 10.1007/s11926-020-0880-3.

31. Nigrovic PA, Raychaudhuri S, Thompson SD. Review: genetics and the classification of arthritis in adults and children. Arthritis Rheumatol 2018; 70: 7-17, DOI: 10.1002/art.40350. 